token treatment of hypertension in the elderly -if there is a need for any treatment at all in such cases? The hypotensive and diuretic effect may be minimal, but all the safer for that, and there will be none of the disturbing side effects of the more potent hypotensives that are often misused in older patients.

Of course, we must always discriminate, and treatment of old people for the conditions I have mentioned is so often a matter of trial and error. My own experience is that there is still a useful place for the humble barbiturates in geriatric practice, and not only in "anaesthesia and the management of epilepsy." Geriatric Unit,
Burghmuir Hospital,
Perth

R G Simpson

\section{Beta-blockers in the treatment of chronic simple glaucoma}

SIR,-Your leading article (24 January, p 180) and the letter from Mr C I Phillips (6 March, p 584) sustain the hope of a full understanding of the constitutional factor in glaucoma and a treatment with a correspondingly high success rate.

In the meantime there is available a treatment of very appreciable utility employing Hydergine, which is claimed to impede the propagation of sympathetic nerve impulses. The effects of this preparation along with reserpine for mild control sedation are described in a paper of $1958 . .^{1}$ The treatment was found effective as a general therapy for chronic glaucoma. In one respect it had a special and measurable value: it was therapeutically successful in $50 \%$ of cases unresponsive to classical treatment-including surgery.

Sheffield

E G MACKIE

Mackie, E G, British fournal of Ophthalmology, 1958

\section{Food choking and the "Heimlich maneuver"}

SIR,-Your leading article on the "Heimlich maneuver" (10 April, p 855) provides a timely reminder of the need for prompt action when a foreign body has been inhaled. However, I should like to inject a note of caution regarding its use in circumstances other than the "cafe coronary." Other foreign bodies may be inhaled, and these may be fatal. Indeed, a young woman died in the Middlesex Hospital in 1973 following inhalation of a piece of chewing gum. ${ }^{1}$

It is this common oral commensal which presents a particular danger to the victims of other trauma, notably racing drivers and other sportsmen. In such circumstances, the "Heimlich maneuver," apart from the risk of gastric laceration, ${ }^{2}$ may aggravate other intraabdominal damage. It would be advisable for all those likely to treat sportsmen who chew gum to be aware of this risk and to be proficient at direct visualisation of the vocal cords.

D G McLintock Chief Medical Officer,

Barnet National Drag Racing Club

1 Scadding, $\mathrm{F} \mathrm{H}$, personal communication

Visintine, R E, fournal of the American Medical Ascociation. 1975, 234, 415.

\section{Varicose veins in developing countries}

SIR,-It has been suggested that varicose veins were probably the commonest disorder presenting to general surgeons in Western countries and that the condition may be present in up to $50 \%$ of an adult population. ${ }^{1} \mathrm{~A}$ detailed survey of a whole community in the USA revealed a prevalence of varicose veins of over $30 \%$ in men and over $50 \%$ in women over the age of 40 years. ${ }^{2}$

In contrast varicose veins appear to be relatively rare among traditionally living people. ${ }^{34}$ In Western countries varicose veins are almost invariably more common in women than in men, and pregnancy is assumed to be a causative factor. Five studies in India indicated that they were more prevalent in men.

In a university department of obstetrics and gynaecology, the legs of 1000 consecutive patients admitted for confinement were examined. In five of these there was evidence of well-established varicose veins, and six other had varicosities of a mild degree, making a total of 11 or approximately $1 \%$. Prior studied the prevalence of varicose veins in Polynesians and found it to be related to contact with Western culture but not to pregnancy when age was taken into consideration Guberan et $a l^{6}$ similarly found no relationship to pregnancy in European women when adjustment was made for age.

This raises the question whether pregnancy per se is a cause of varicose veins or whether it is merely a factor exacerbating existing venous defects. Further epidemiological studies of this nature are required to help to clarify the aetiology of such a common condition as varicose veins.

C Phillips

Medical College

Professor and Head of of Obstetrics and Gepartment

Amritsar

D P BURKITT

Medical Research Council,

External Scientific Staff,

172 Tottenham Court Road,

Lancet, 1975, 2, 311

2 Coon, W W, et al. Circulation, 1973, 48, 839

Burkitt, D P, British Medical fournal, 1972, 2, 556

Burkitt, D P, in Refined Carbohydrate Foods and Disease, ed D P Burkitt and H C Trowell. London
and New York, Academic Press, 1975.

s Prior, I A M, Proceedings of Pan-Pacific Surgical

Guberan, E, et al, fournal for Vascular Disease, 1973,

\section{Doppler angiography}

SIR,-In their description of Doppler angiography in the detection of occult deep vein thrombosis, Dr T K Day and others (13 March, p 618) have given a rather too gloomy picture of the usefulness of the Doppler ultra-sound flowmeter. They state that in our series' two patients died from pulmonary embolism. In fact one patient died and another presented with massive leg swelling without prior detection of thrombosis. The flowmeter accurately detected two other femoral vein thrombi, and in two further patients calf thrombi were detected by tenderness on examination. These results are not impressive, and at the time we concluded that effective prophylaxis is far preferable to attempts at early detection with the apparatus now available.

In Dr Day's series Doppler angiography failed to detect $31 \%$ of the non-occlusive femoral and popliteal thrombi, and it is to be hoped that further work in simplification and increased accuracy, to which he refers, will produce a more useful method of detection.

C R K RICKFORD

St Thomas's Hospital

London SE1

Negus, D, and Rickford, C R K, Proceedings of the Roval Society of Medicine, 1974, 67, 703.

\section{Improving the hospital service}

SIR,-Some points in Dr A L Bussey's (20 March, p 714) and Mr P A Hill's (10 April, p 902) criticisms of my article warrant attention. Tables of "hard" facts were part of the original draft, but were removed, because valid statistical comparison was impossible, and by editorial pruning. None the less, conclusions can surely be drawn when data are widely disparate such as a three-fold difference in the number of ancillary and administrative staff employed, when the overall workload is similar. I think the following figures on workload and staff employed for 1972 will satisfy your correspondents on these points.

\begin{tabular}{|c|c|c|c|}
\hline & & $\begin{array}{l}\text { Dutch } \\
\text { Hospital }\end{array}$ & UK \\
\hline Admissions & & 6,800 & 5,685 \\
\hline Inpatient operations & & & 39 \\
\hline Outpatient operations & & 1,823 & 1,300 \\
\hline Outpatient consultation & & 70,089 & 63,700 \\
\hline Bed occupancy .. & . & $91 \%$ & 81 \\
\hline Catchme & $\ldots$ & 120,000 & 110,000 \\
\hline $\begin{array}{l}\text { Staff } \\
\text { Admir }\end{array}$ & & 19 & 49 \\
\hline /engineering & & 4 & 24 \\
\hline Ancillary & & 51 & 167 \\
\hline $\begin{array}{l}11 \text { staff (excl. } \\
\text { specialists/consultant }\end{array}$ & & 280 & 541 \\
\hline
\end{tabular}

I feel both correspondents are being deliberately ingenuous on some points. As regards Dr Bussey's comment on running costs, I had innocently used the 1974 exchange rate in my calculations, but the 1972 rate of 8.2 guilders to the pound would give $£ 1 \cdot 2$ million for the Dutch hospital, which includes capital repayment, against $£ 1.4$ million for the UK hospital, which does not.

Mr Hill, in adding up blocks, should surely have noticed those on the bottom line on the Dutch management diagram had been combined into one for the UK hospital. This was due to the editorial pruning. My point remains that the UK system is more complicated, employs more personnel. especially if area and region are taken into account, and is less responsive to local needs.

There has been local over-provision of beds in Holland, a fault now remedied by stricter licensing. On the credit side hospitals are up to date in contrast to the large percentage of old, inefficient buildings in the United Kingdom.

Like your correspondents I hope to see an improvement in the delivery of health care, and this was my motive in presenting another system for comparison. A favourable reception, particularly among a wide range of people who work in the hospital service, has convinced me that it was a useful exercise.

J F MURRAY

Kidderminster Postgraduate Medical Centre, Kidderminster 